\title{
Reaction Kinetics Modelling for Dry Anaerobic Digestion of Hura Crepitans Invasive Species Lignocellulosic Biomass
}

\section{Akinola David Olugbemide ( $\sim$ akinoladave@gmail.com )}

Federal Polytechnic Auchi https://orcid.org/0000-0001-5200-364X

Blaž Likozar

National Institute of Chemistry Slovenia: Kemijski institut

\section{Ana Oberlintner}

National Institute of Chemistry Slovenia: Kemijski institut

\section{Uroš Novak}

National Institute of Chemistry Slovenia: Kemijski institut

\section{Ekebafe Lawrence}

University of Lagos

\section{Research Article}

Keywords: invasive plant species, waste lignocellulose valorisation, biomass anaerobic digestion, biogas production process, chemical reaction kinetics, mechanistic model simulations

Posted Date: November 30th, 2021

DOI: https://doi.org/10.21203/rs.3.rs-1101352/v1

License: (1) This work is licensed under a Creative Commons Attribution 4.0 International License. Read Full License 


\section{Abstract}

In this research study, the impact of the feedstock to the inoculum $(F / I)$ amount ratio in the dry anaerobic digestion (DAD) of Hura crepitans leaves was evaluated. Measured biogas volumes, as well as the chemical kinetic predictions for exponential, logistic and Gompertz model, depicting the agreement of the simulations over time, were also determined. From the $F / /$ equivalents 2,4 and 6 at $22 \%$ of packed total solids, which were considered in analysis test procedure, the DAD digester with $\mathrm{F} /$ / number 4 was the most promising in terms of biogas' production rate. Its daily methane/carbon dioxide was $690 \mathrm{~mL}$, while cumulative generation productivity was greater than $2 \mathrm{~L} /$ sample, respectively. On the other hand, the DAD reaction with $\mathrm{F} / /$ contained 6 , recorded the lowest related expressed primary matter of $<1 \mathrm{~L}$. An associated early commencement of the organic material breakdown in all bio vessels was indicative of a good start-up phase, which is one of the challenges, often encountered in DAD process. Furthermore, applied experimental methods revealed the direct correlation phenomena between biodegradability physical constants, measured molecular $\mathrm{CH}_{4} / \mathrm{CO}_{2}$ synthesis and simulations. Hura crepitans being an invasive plant species makes its lignocellulosic fractions desired in terms of valorisation, as it is not competing with agricultural crop products. Modelling can, moreover, contribute to consecutive operation optimisation, scaling and integrating, also taking dynamics under consideration. As opposed to biorefining wood residues, where individual cellulose, hemicellulose or lignin biopolymers can be attained, degradation to yield $\mathrm{CH}_{4}$ is robust, as well as compatible in combustion.

\section{Introduction}

Dry anaerobic digestion (DAD) also known as solid-state anaerobic digestion (SSAD) refers to a process operated at a total solid of $20-55 \%$ [1]. It has gained more prominence in recent years because of the benefits associated with it in comparison to liquid or wet anaerobic digestion (LAD or WAD). These benefits include mitigation of floating and stratification of substrates in the digester, lower energy requirement, lower water consumption, less wastewater generation [2, 3].

DAD has been used to digest different organic wastes such as municipal solid wastes, agricultural wastes, with promising results that have encouraged further research efforts [4, 5]. DAD can be operated under the three temperature regimes used in WAD namely psychrophilic, mesophilic and thermophilic temperature. However, mesophilic and thermophilic temperature regimes are commonly used with thermophilic outperforming mesophilic system in terms of biogas yield but due to its sensitivity to temperature fluctuations and high cost of operation (energy requirement), mesophilic system is still preferred for commercial operation [6]. Zhu and Jha [7] conducted DAD of cow dung under psychrophilic conditions with a significant increase in yield when the amount of low temperature adapted inoculum was increased from $30-50 \%$. Li et al. [8] conducted DAD of raw and pretreated corn stover at mesophilic and thermophilic temperatures of $37^{\circ} \mathrm{C}$ and $55^{\circ} \mathrm{C}$ with some encouraging results. In another study, DAD of rice straw was carried out at three feedstock-to-inoculum ratios of 6,8 and 10 under mesophilic and thermophilic conditions with thermophilic generally performing better than the mesophilic temperature regime [9]. 
Feedstock-to-inoculum ratio plays a significant role in process efficiency of DAD. It has been observed that operating DAD at a higher F/I could lead to process failure due to accumulation of volatile fatty acids (VFAs) [10].

There is need therefore to explore more feedstocks in order to discover their biogas potentials under this AD system and by so doing enhancing competiveness with WAD system. Hura crepitans (figure 1), which is also known as the Sandbox tree, is a fast-growing, semi-deciduous tree with a heavy bole and limbs that are covered in spines [11]. In closed forests, it can grow up to 50 meters tall, but in more open sites, it is usually rather smaller, in the range of $12-20$ metres [12]. The straight, cylindrical bole is often basally swollen, or has small buttresses. It can be unbranched for up to 30 metres and boles $200 \mathrm{~cm}$ in diameter have been reported, though $90-150 \mathrm{~cm}$ is more common [13].

Hura crepitans Linns which belongs to the family Euphorbiaceae has ovate leaves that could grow up to two feet wide $[14,15,16]$. Hura crepitan leaves are one of the unexplored materials that can be used as a potential feedstock for biogas production. There have been various reports on the uses of different parts of Hura crepitans tree in literature but none to the best of authors' knowledge, has been reported on the production of biogas from Hura crepitans leaves using DAD. The author in a previous work produced biogas from Hura crepitans leaves but with WAD [17]. The aim of this study was to determine the biogas potential of Hura crepitans leaves under DAD system with focus on the effect of feedstock-to-inoculum ratio on production yield.

\section{Materials And Methods}

Hura crepitans Linns leaves were collected from Auchi, Etsako West Local Government Area, Edo State, Nigeria. The leaves were sun-dried, ground and passed through 300 microns mesh sieve and stored in an air-proof plastic bottle prior to DAD process and analysis. The cow dung was collected from a local cattle market and stored in an anaerobic condition for 30 days before it was used as inoculum.

\section{Dry Anaerobic Digestion of Hura crepitans Leaves}

Digesters were prepared with $\mathrm{F} / \mathrm{I}$ ratios 2,4 and 6 based on the volatile solids (VS). Appropriate amount of water was added to obtain $22 \%$ total solids (TS). The samples were charged into $1 \mathrm{~L}$ glass reactors and tightly closed with rubber stoppers. The digesters were codenamed DAD2, DAD4 and DAD6, where the number denotes the F/I ratio, respectively. Biogas volume was measured by water displacement method every 24 hours while the cumulative volume was calculated. All tests were conducted in duplicate at ambient temperature of $36 \pm 2^{\circ} \mathrm{C}$ for a retention time of 30 days. Reactors were manually shaken once a day for improved substrate-microorganism contact.

\section{Analytical Methods}

Hura crepitans leaves were analyzed for TS, VS, ash, carbon, nitrogen, extractives, lignin, cellulose and hemicellulose while the inoculums was analyzed for ash, TS and VS according to standard methods [18, 
19]. The initial and final $\mathrm{pH}$ values of the slurries were determined using a hand-held digital $\mathrm{pH}$ meter (Hanna Instruments, Italy).

\section{Kinetic Studies}

The kinetics of the anaerobic digestion process was evaluated using a first-order kinetic model to determine the biodegradability constants according to the following equations:

$$
G=G_{m}[1-\exp (-k o t)(1)
$$

Equation (1) was linearized to give equation (2)

$$
\ln \left[\frac{G m}{G_{m}-G}\right]=\operatorname{kot}(2)
$$

A plot of $\ln \left[\frac{G m}{G_{m}-G}\right]$ vs time gave the biodegradability constants as shown in Table 2

In order to describe cumulative biogas yield $(P)$, exponential, logistic and Gompertz model were used as Equations $3-5$, respectively. $P_{m}$ represents maximal $P, t$ time, $k$ (digestion) reaction rate constant, $R_{m}$ highest biogas production and $\lambda$ initial process lag.

$$
P(t)=P_{m}\left(1-e^{-k t}\right)
$$

3

$$
P(t)=P_{m}\left(1+e^{\left(4 R_{m}(\lambda-t) / P_{m}+2\right)}\right)^{-1}
$$

4

$$
P(t)=P_{m} \exp \left(-e^{\left(e R_{m}(\lambda-t) / P_{m}+1\right)}\right)
$$

5

\section{Results And Discussion}

Physicochemical properties of the samples are shown in Table 1. The ash, TS and VS were determined to be $14.22 \%, 97.00 \%$ and $82.79 \%$ for Hura crepitans leaves and $5.42 \%, 30.14 \%$ and $24.72 \%$ for the inoculum. The $\mathrm{C} / \mathrm{N}$ ratio Hura crepitans leaves was 32.2 while its lignin, cellulose and hemicellulose contents were measured to be $28.26 \%, 32.70 \%$ and $39.05 \%$ respectively. As earlier mentioned, Hura crepitans leaves were thoroughly mixed with the inoculum and water added to produce the three F/I ratios used in the DAD. 
Sample DAD6 had the highest lignin content while DAD2 had the least. Lignin usually forms a complex network with the carbohydrates thus making the lignocellulosic biomass recalcitrant to microbial degradation, which in turn could lower biogas yield [9].

Both samples DAD2 and DAD4 had higher contents of hemicellulose and cellulose than DAD6 which are the major components from which biogas is produced [20]. The highest ash content was found in sample DAD2 followed by DAD6. The cellulose content for DAD2 was close to $51.30 \%$ reported for organosolvpretreated pinewood at $150^{\circ} \mathrm{C}$ for 30 minutes by Mirmohamadsadeghi [21]. The hemicellulose content on the other hand was higher than $19.1 \%$ reported for corn cob by Liew et al [22].

The $\mathrm{C} / \mathrm{N}$ ratios of DAD4 and DAD6 were well outside the range recommended for $A D$, that is, between 20:1 and 30:1 [23] while DAD2 was slightly above (30.95\%) the range. The C/N ratios of DAD4 and DAD6 were however, below $97.6 \%$ reported for sunflower stalk by Kurt et al. [24]. Despite the high $\mathrm{C} / \mathrm{N}$ ratios (with the exception of DAD2) there was still reasonably high biogas production. This observation has been reported in literature $[25,26]$ which could be attributed to the fact that $\mathrm{C} / \mathrm{N}$ is not the only parameter responsible for effective running of AD. The overview done by Deublein and Steinhauser (2011) have pointed out no direct correlation between $\mathrm{C} / \mathrm{N}$ ratio and biogas yield. [27] Their presumable conclusion was that $\mathrm{C} / \mathrm{N}$ ratio might not in any way affect biomethane (biogas) yield. They based their argumentation on a three-year study on buffalo manure collected under varying conditions with $\mathrm{C} / \mathrm{N}$ ratios ranging from 9 to 50 . Their findings showed that there was significant biomethane production outside the range often reported in literature as optimal for AD. The argument can be laid to rest when we consider the fact that there are other factors that contribute to biogas production beside $\mathrm{C} / \mathrm{N}$ ratio. There is need for further research in this area because of the contradictory results that have been reported in literature in order to have a better understanding of the role of $\mathrm{C} / \mathrm{N}$ ratio on $\mathrm{AD}$. However, substrates high in $\mathrm{C} / \mathrm{N}$ ratio, such as samples DAD4 and DAD6 could serve as good co-digestion feedstocks for substrates that are low in carbon content [27]. 
Table 1

Physicochemical properties of the samples used in dry anaerobic digestion

\begin{tabular}{|llllll|}
\hline Parameters & $\begin{array}{l}\text { Hura crepitans } \\
\text { leaves }\end{array}$ & Inoculum & DAD2 & DAD4 & DAD6 \\
\hline Ash content (\%) & $14.22 \pm 0.15$ & $5.42 \pm 0.31$ & $15.32 \pm 0.17$ & $13.54 \pm 0.76$ & $14.29 \pm 0.54$ \\
\hline TS content (\%) & $97.00 \pm 0.05$ & $30.14 \pm 0.05$ & ND & ND & ND \\
\hline VS content (\%) & $82.79 \pm 0.15$ & $24.72 \pm 0.3$ & ND & ND & ND \\
\hline Carbon content (\%) & $47.66 \pm 0.08$ & ND & $47.05+0.05$ & $47.73+0.42$ & $47.62+0.30$ \\
\hline $\begin{array}{l}\text { Nitrogen content } \\
(\%)\end{array}$ & $1.48+0.28$ & ND & $1.52+0.83$ & $0.63+0.04$ & $0.57+0.07$ \\
\hline C/N ratio & 32.20 & & & & \\
\hline Lignin (\%) & $28.26 \pm 0.74$ & ND & 30.95 & 75.76 & 83.54 \\
\hline Cellulose (\%) & $32.70+0.34$ & ND & $50.33+0.04$ & $45.76+0.29$ & $38.58+0.5$ \\
\hline Hemicellulose (\%) & $39.05 \pm 0.39$ & ND & $22.91+0.55$ & $17.75+0.25$ & $16.94+1.03$ \\
\hline ND - not determined & & & & & \\
\hline
\end{tabular}

The $\mathrm{pH}$ values of the initial and final samples are shown in figure 2. The values ranged from 5.4-8. The initial $\mathrm{pH}$ of $\mathrm{F} / \mathrm{I} 2$ was 8.00 while the final $\mathrm{pH}$ was 5.60 . For $\mathrm{F} / \mathrm{I} 4$ the initial $\mathrm{pH}$ was 7.60 while the final $\mathrm{pH}$ was 5.40. Digester $\mathrm{F} / \mathrm{I6}$ also had initial $\mathrm{pH}$ of 7.60 but a final $\mathrm{pH}$ of 6.00 . Overall, there was a decline in $\mathrm{pH}$ values in all the digesters at the end of the anaerobic digestion, a fact that has been attributed to accumulation of volatile fatty acids [28].

\section{Daily And Cumulative Biogas Production}

Figure 3 shows daily and cumulative biogas production from the three weighted samples. There was no lag phase in all the digesters as production commenced within the first 24 hours which was indicative a good start up/hydrolysis stage in the DAD process. It has been observed that operating DAD at a higher $\mathrm{F} / \mathrm{I}$ ratio could slow down the initial stage as shown elsewhere [10] but the results from this study revealed that the $\mathrm{F} / \mathrm{I}$ ratios adopted were appropriate for rapid beginning phase of the DAD. Digester DAD6 peaked earlier (day 7) than other digesters with peak production of $280 \mathrm{ml}$. Digester DAD2 peaked on day 8 with $410 \mathrm{ml}$ while digester DAD4 achieved its highest peak value on day $18(690 \mathrm{ml})$ which was longer than other digesters. Biogas continued till the last day of the experiments which shows that the process efficiency was healthy which could be as a result of no or low inhibitory substances in the system.

In this study, the sample DAD6 with highest lignin content produced the least amount of biogas. Although no clear relationship between the amount of biogas produced and lignin contents of the substrates in this study, yet the least biogas produced was from the sample with the highest lignin content. 
Results of cumulative biogas production revealed that digester DAD4 was 2.4 fold higher than that of DAD6 which produced the least volume $(940 \mathrm{~mL})$ of biogas. Digester DAD2 produced a volume of 2005 $\mathrm{ml}$ while digester DAD4 produced a highest volume of gas with a total of $2210 \mathrm{ml}$. This shows that biogas production is best carried out at this $\mathrm{F} / \mathrm{I}$ ratio.

\section{Kinetic Study}

There was a direct correlation between biodegradability constant and biogas yield. DAD4 with the highest biogas yield had the highest constant biodegradability value of $\left(K_{0}\right)$ of $1.110 \mathrm{~d}^{-1}$ followed by DAD2 0.569 $\mathrm{d}^{-1}$ with sample DAD6 having the least value of $0.347 \mathrm{~d}^{-1}$. The results revealed that digester DAD6 had highest utilization of the substrate, which translated to increased biogas production compared to other digesters. The $\mathrm{K}_{\mathrm{o}}$ for DAD2 was higher than 0.9185 reported for $3 \%$ Organosolv pretreated rice husk by Olugbemide et al. [17].

Table 2

Chemical kinetics parameters regressed for various proposed models/data.

\begin{tabular}{|c|c|c|c|}
\hline Data & DAD2 & DAD4 & DAD6 \\
\hline \multicolumn{4}{|l|}{ Exponential } \\
\hline$P_{m} / \mathrm{L}$ & 2.05 & 2.21 & 1.01 \\
\hline$k /$ day $^{-1}$ & 0.146 & 0.064 & 0.094 \\
\hline \multicolumn{4}{|l|}{ Logistic } \\
\hline$P_{m} / \mathrm{L}$ & 1.92 & 2.58 & 0.90 \\
\hline$R_{m} /\left(\mathrm{L} \mathrm{day}^{-1}\right)$ & 0.272 & 0.124 & 0.066 \\
\hline$\lambda /$ day & 1.80 & 5.72 & 0.24 \\
\hline \multicolumn{4}{|l|}{ Gompertz } \\
\hline$P_{m} / \mathrm{L}$ & 1.94 & 3.42 & 0.92 \\
\hline$R_{m} /\left(\mathrm{L} \mathrm{day}^{-1}\right)$ & 0.273 & 0.102 & 0.068 \\
\hline$\lambda /$ day & 1.58 & 3.45 & 0.12 \\
\hline
\end{tabular}

Results show that exponential kinetic model provides the poorest measurement agreement, not being able to describe the lag in production, which is clearly seen, in particular with the data 2, where maximal production rate is achieved only after day 17 . Logistic or Gompertz models provide approximately the same prediction/ measurement agreement, whereas the data 1 or 3 can be described excellently, while for 2 , we not only see a lag in production, but also a bimodal digestion process. Correspondingly, this hints 
towards two predominant fractions, which are being digested at a much dissimilar rate/lag of cascade digestion process, which should have been described by a reaction in series kinetic model, regressing also intermediate.

\section{Conclusion}

Hura crepitan leaves, as one of the underutilized feedstocks, have shown potential to be used for biogas production. Herein, dry anaerobic digestion (DAD) of Hura crepitans leaves was carried out with the aim of determining the effect of different feedstock-to-inoculum ratios on biogas production. The results revealed that anaerobic digestion of Hura crepitans leaves carried out at F/14 (22\% TS) was the optimum condition for generating maximum amount of biogas. However, in terms of peak value, digester DAD2 outperformed other digesters in reaching its maximum peak value at the earliest time in comparison to other digesters. The use of Hura crepitan leaves for biogas production could help increase the number of viable substrates that can be used for energy recovery via $A D$; more so now that the technology is gaining prominence around the world. Further studies need to be done though to explore how best to improve biogas yield from this underutilized but readily available substrate.

\section{Declarations}

\section{Declaration of Competing Interest}

The authors declare that there is no conflict of interest regarding the publication of this article.

\section{References}

1. Cui Z, Shi J, Li Y (2011) Solid-state anaerobic digestion of spent wheat straw from horse stall. Bioresour Technol 102:9432-9437

2. Wedwitschka H, Gallegos D, Tietze M, Reinhold J, Jenson E, Liebetrau J, Nelles M (2020) Effect of Substrate Characteristics and Process Fluid Percolation on Dry Anaerobic Digestion Processes. Chem Eng Technol 43:59-67

3. Ge X, Xu F, Li Y (2016) Solid-state anaerobic digestion of lignocellulosic biomass: Recent progress and perspectives. Bioresour Technol 205:239-249

4. Khairuddin N, Abd Manaf L, Hassan MA, Halimoon N, Ghani WA (2016) High solid anaerobic codigestion of household organic waste with cow manure for mass and energy recovery. Polish Journal of Environmental Studies 22:1549-1554

5. Suksong W, Promnuan K, Seengenyoung J, Sompong O (2017) Anaerobic Co-digestion of palm oil mill waste residues with sewage sludge for biogas production. Energy Procedia 1:789-794

6. Zhou H, Wen Z (2019) Solid-state anaerobic digestion for waste management and biogas production. Solid State Fermentation 147:68 
7. Zhu G, Jha AK (2013) Psychrophilic dry anaerobic digestion of cow dung for methane production: Effect of inoculum. Sci Asia 1:500-510

8. Li Y, Zhang R, He Y, Liu X, Chen C, Liu G (2014) Thermophilic solid-state anaerobic digestion of alkaline-pretreated corn stover. Energy Fuels 28:3759-3765

9. Li C, Zhou Y, Lu W, Nges IA (2019) Enhancement of the solid-state anaerobic digestion of rice straw by liquor supplementation. Bioresource Technology Reports 1:59-65

10. Riya S, Meng L, Wang Y, Lee CG, Zhou S, Toyota K, Hosomi M (2020) Dry Anaerobic Digestion for Agricultural Waste Recycling. InBiogas IntechOpen 1-21

11. Barwick M (2004) Tropical and Subtropical Trees. A Worldwide Encyclopaedic Guide. Thames \& Hudson, Publisher, London

12. Huxley A (1992) The New RHS Dictionary of Gardening. MacMillan Press

13. Oderinde RA, Ajayi I, Adewuyi A (2009) Preliminary Toxicological Evaluation and Effect of the Seed oil of Hura crepitans and Blighia unijugata Bak on the lipid profile of rat. EJEAFChe 8:209-217

14. Longwood FR (1962) Present and Potential Commercial Timbers of the Caribbean. USDA Agricultural Handbook No. 207. USDA Forest Service, Washington, DC

15. Abdulkadir MN, Amoo IA, Adesina AO (2013) Chemical composition of Hura crepitans seeds and antimicrobial activities of its oil. International Journal of Science and Research 2:440-445

16. Okolie PN, Uaboi-Egbenni PO, Ajekwene AE (2012) Extraction and quality evaluation of Sandbox Tree seed (Hura crepitans) oil. World Journal of Agricultural Sciences 8:359-365

17. Olugbemide AD, Lajide L, Adebayo A, Owolabi BJ (2016) Kinetic study of biogas production from raw and solid-state organosolv pretreated rice husk. J Biofuels 7:110-118

18. AOAC Association of Official Analytical Chemists (1990) Official Methods of Analysis of the Association of Official Analytical Chemists 14th edn. Washington DC

19. ASTM American Society for Testing and Materials (1972) Standard Methods of Test for AlcoholBenzene Solubility of Wood ASTM D1 107-56. ASTM, West Conshohocken

20. Wojcieszak D, Przybył J, Ratajczak I, Goliński P, Janczak D, Waśkiewicz A, Szentner K, Woźniak M (2020) Chemical composition of maize stover fraction versus methane yield and energy value in fermentation process. Energy 198:117258

21. Mirmohamadsadeghi S, Karimi K, Zamani A, Amiri H, Horvath IS (2014) Enhanced solid-state biogas production from lignocellulosic biomass by organosolv pretreatment. Biomed Res Int 2014:1-6

22. Liew LN, Shi J, Li Y (2012) Methane production from solid-state anaerobic digestion of lignocellulosic biomass. Biomass Bioenergy 46:125-132

23. Konrad O, Akwa JV, Koch FF, Lumi M, Tonetto J (2016) Quantification and characterization of the production of biogas from blends of agro-industrial wastes in a large-scale demonstration plant. Acta Scientiarum Technology 38:415-421

24. Kurt G, Doluk R, Yoruklu HC, Demir A, Ozkaya B (2021) Methane Production Potential of Rumen Pretreated Lignocellulosic Wastes. https://doi.org/10.21203/rs.3.rs-169652/v1. Research square 
25. Lin Y, Ge X, Li Y (2014) Solid-state anaerobic co-digestion of spent mushroom substrate with yard trimmings and wheat straw for biogas production. Bioresour Technol 1:468-474

26. Song Z, Zhang C, Yang G, Feng Y, Ren G, Han X (2014) Comparison of biogas development from households and medium and large-scale biogas plants in rural China. Renew Sustain Energy Rev 33:204-213

27. Deublein D, Steinhauser A (2011) Biogas from Waste and Renewable Resources: An Introduction. John Wiley and Sons, New Jersey

28. Guarino G, Carotenuto C, Di Cristofaro F, Papa S, Morrone B, Minale M (2016) Does the C/N ratio really affect the Bio-methane Yield? A three years investigation of Buffalo Manure Digestion. Chem Eng Trans 49:463-468

29. Magdalena JA, Greses S, González-Fernández C (2019) Impact of organic loading rate in volatile fatty acids production and population dynamics using microalgae biomass as substrate. Sci Rep 9:1-11

\section{Figures}
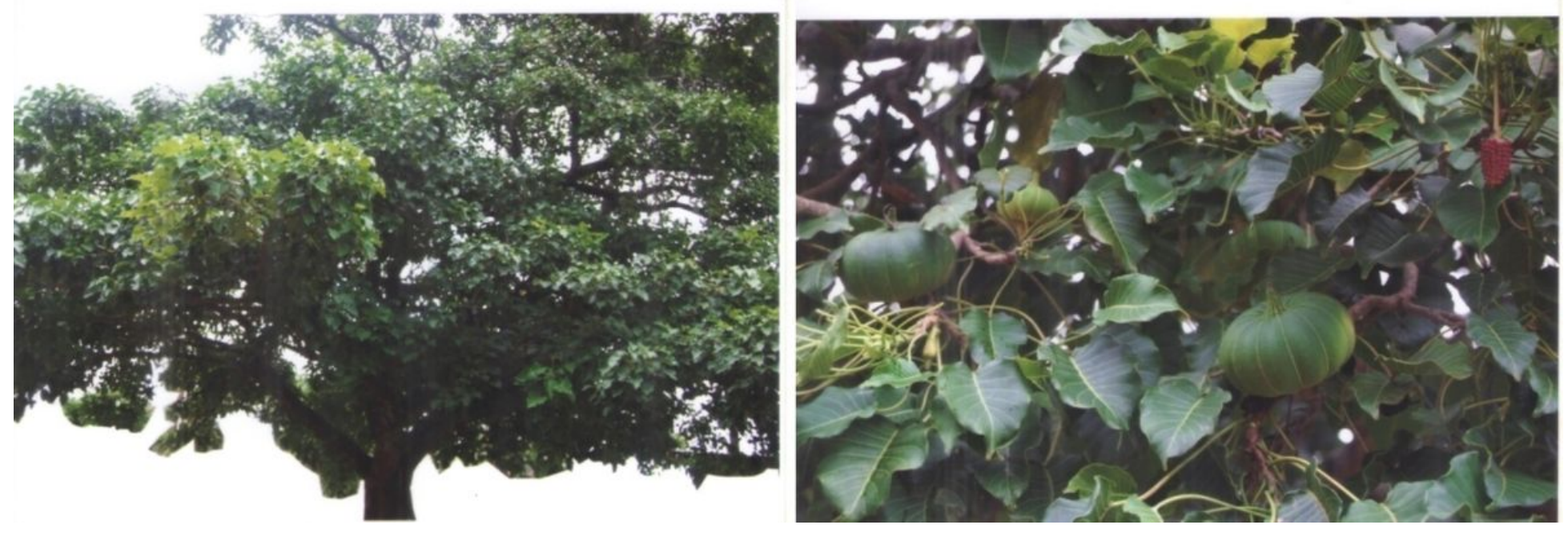

Figure 1

a. Hura crepitans tree b. Hura crepitans leaves and seeds 

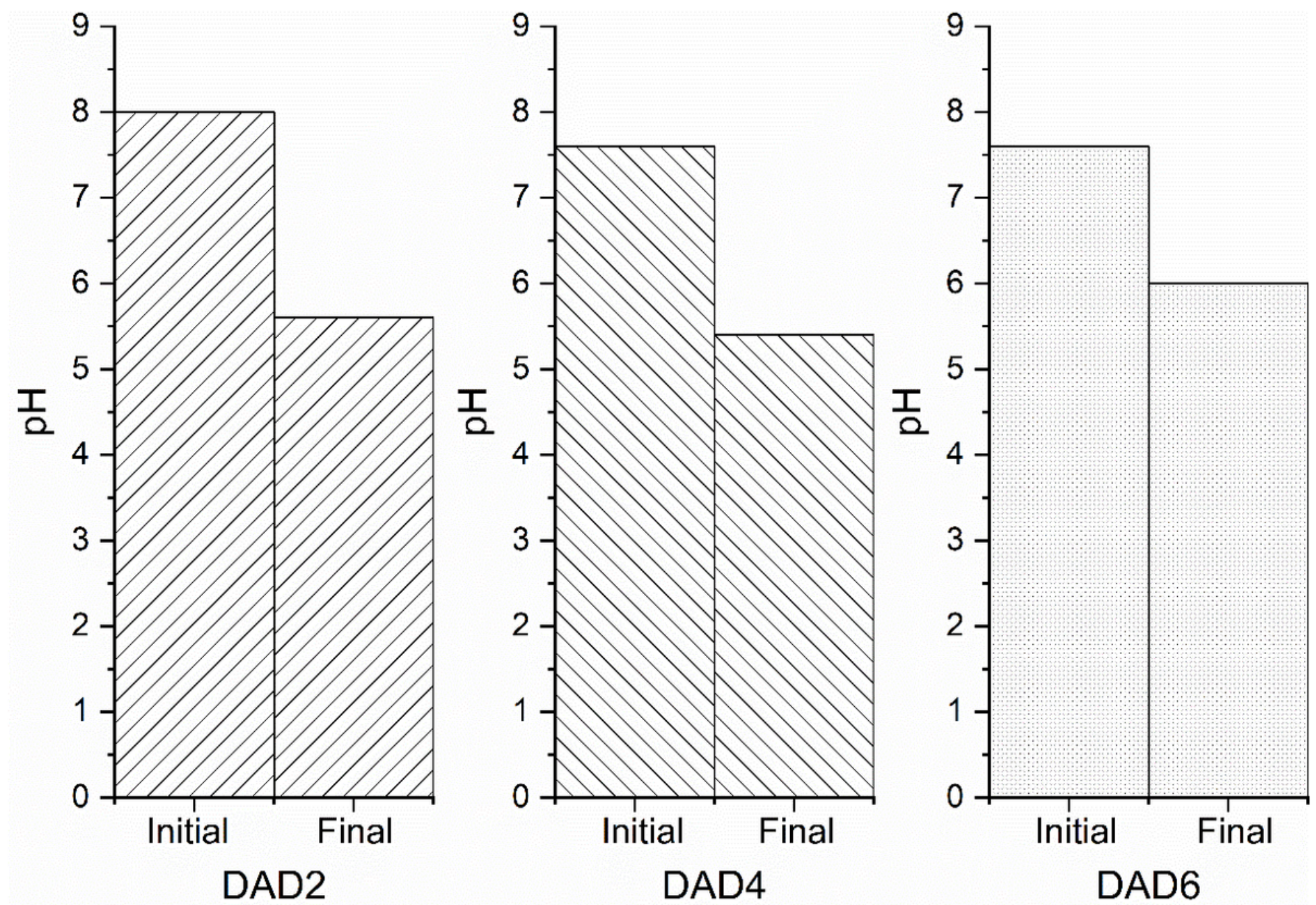

Figure 2

Initial and final pH values of DAD2, DAD4 and DAD6. 

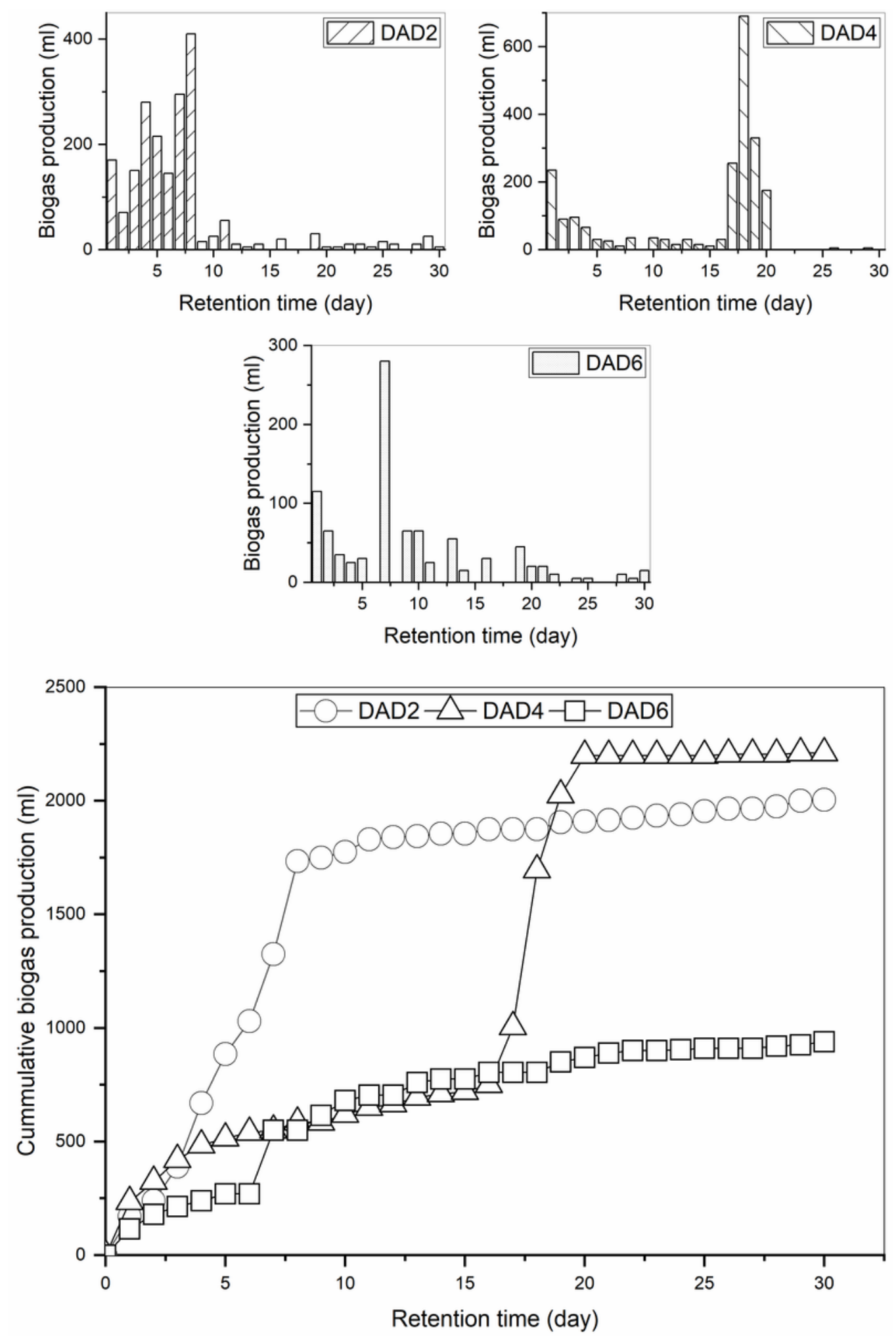

Figure 3

Daily and cumulative biogas production of digesters DAD2, DAD4 and DAD6. 


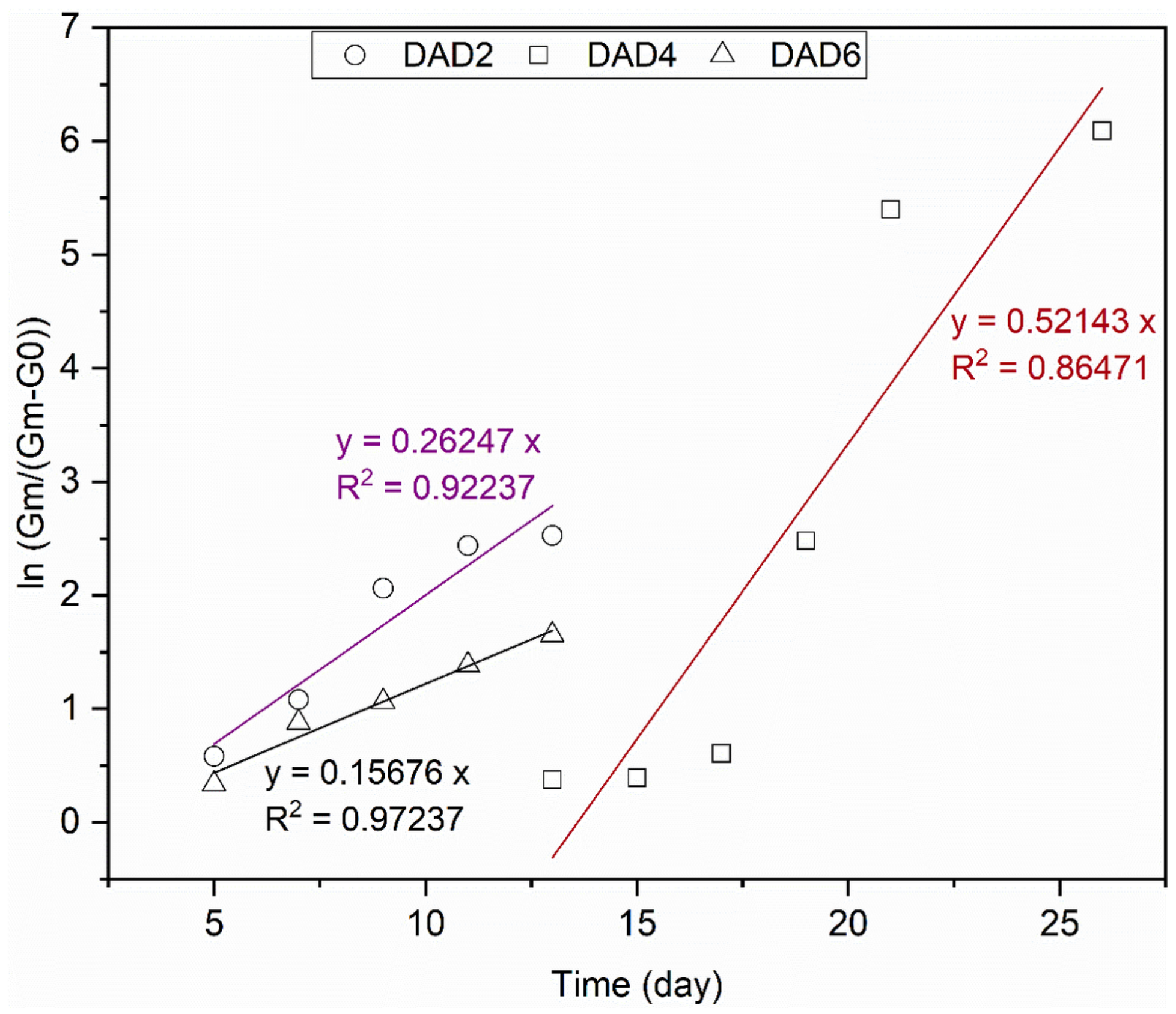

Figure 4

Plot of In Gm/Gm-Go against retention time of digesters DAD2, DAD4 and DAD6. 

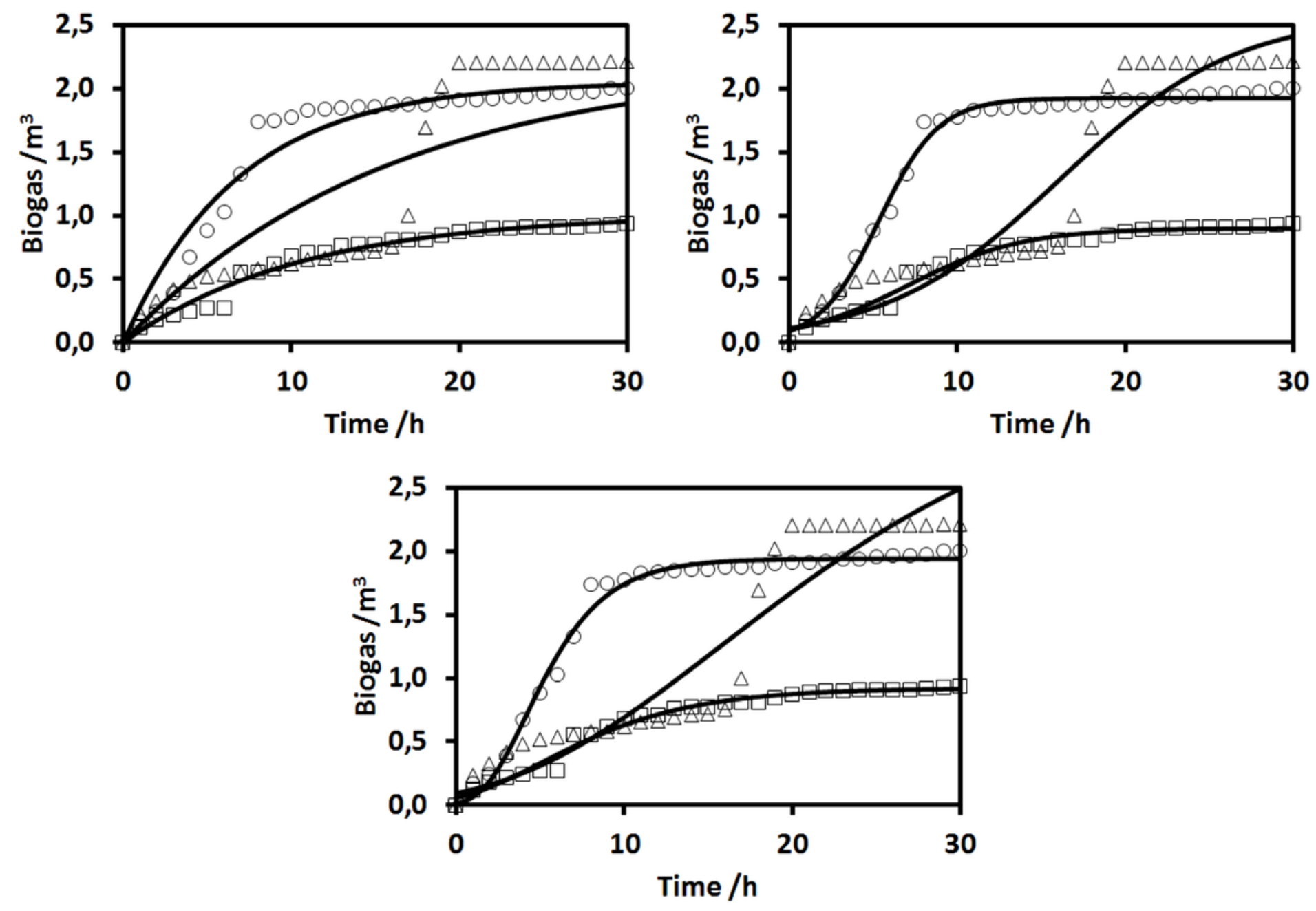

Figure 5

Measured biogas volumes (the circles for 1 , triangles for 2 and squares for 3 ), as well as the chemical kinetic predictions for exponential (top left), logistic (top right) and Gompertz (bottom) model, depicting the agreement of the simulations over time. 